\title{
DEPOSIÇÃO DE CALDA EM CAFEEIRO CONILON APLICADA POR PULVERIZAÇÃO PNEUMÁTICA
}

\author{
Pablo Souto Oliveira ${ }^{1}$ \\ Edney Leandro da Vitória ${ }^{2}$ \\ Luciano Canal ${ }^{3}$ \\ Yago Soares Avancini ${ }^{4}$ \\ Carla da Penha Simon ${ }^{5}$ \\ Tatiana Fiorotti Rodrigues ${ }^{6}$ \\ Déborah Hoffmam Crause ${ }^{7}$
}

Resumo: O Espirito Santo é destaque entre os estados brasileiros produtores de café conilon (Coffea canephora), com cerca de $80 \%$ da produção nacional. Com a finalidade de realizar tratamentos de cultivos de alta densidade foliar, a pulverização pneumática tem sido empregada nas culturas de café e citros. Objetivou-se neste trabalho, avaliar a deposição de calda na copa de cafeeiros da variedade conilon aplicada por pulverização pneumática. Foi utilizado um delineamento experimental inteiramente casualizado, com quatro repetições, em um esquema de parcelas subdivididas sendo oito linhas de plantio de cafeeiro, dois lados e três terços das plantas. $A$ área foliar foi obtida por um medidor de área foliar marca LI-COR, modelo LI-3100C, por leitura individual. Houve diferença significativa no desdobramento da interação "lado das plantas x terço das plantas" entre os terços em relação ao lado frontal da pulverização, com maior deposição no terço superior. Ocorreu maior deposição até a distância de 10,8 m; o lado frontal ao pulverizador houve maior deposição no terço médio e superior e o lado posterior a deposição foi semelhante nos três terços.

Palavras-chave: Aplicação de defensivos; Uniformidade; Conjunto trator pulverizador.

\footnotetext{
1 Agronomia/Universidade Federal do Espírito Santo, Campus São Mateus, Brasil. E-mail: pablosanto13@hotmail.com.

2 Professor Titular da Universidade Federal do Espírito Santo, Campus São Mateus, Brasil. E-mail: vitoria.edney@gmail.com.

3 Agronomia/Universidade Federal do Espírito Santo, Campus São Mateus, Brasil. E-mail: contatcanalluc@hotmail.com.

4 Agronomia/Universidade Federal do Espírito Santo, Campus São Mateus, Brasil. E-mail: yagosoaresavancini@hotmail.com.

5 Agronomia/Universidade Federal do Espírito Santo, Campus São Mateus, Brasil. E-mail: carlasimon2009@hotmail.com.

6 Agronomia/Universidade Federal do Espírito Santo, Campus São Mateus, Brasil. E-mail: tati_fiorotti@hotmail.com.

7 Agronomia/Universidade Federal do Espírito Santo, Campus São Mateus, Brasil. E-mail: deborahlife2014@hotmail.com.
} 